Галисия: Finisterre или перекресток дорог?

Аннотация: В статье анализируется культурная и языковая ситуация в Галисии. Отмечена причастность Галисии ко многим важным европейским событиям культурного и религиозного характера (поиски общих корней с кельтским миром, паломническая деятельность, тесные культурные связи с Провансом в средние века и т. д.). Рассматриваются в том числе споры между сторонниками интеграции с Португалией и их противниками, а также вопросы нормализации и кодификация галисийского языка, имеющего статус одного из коофициальных языков на территории Испании.

Ключевые слова: галисийский язык, культурная и языковая ситуация в Галисии

E.A. Grinina (Moscow, Russia)

\title{
Galicia: Finisterre or the Crossroads?
}

Abstract: The article comprises the cultural and language situation in Galicia and its interrelations with the other world. e. g. search for common roots with The Celtic world, pilgrimage activities, close cultural relations with Provence in the Middle Ages etc. The disputes between the supporters of integration with Portugal and their opponents are, the normalization and codification of the Galician language, which has the status of one of the official languages in Spain are discussed.

Key words: The Galician language, cultural and language situation in Galicia

Возможно, эту статью следовало бы назвать «Mi visión de Galicia», поскольку ее содержание составляют размышления, навеянные посещением этого интереснейшего региона Испании, и, разумеется, интерпретация и оценка некоторых важных событий и явлений носит чисто субъективный характер.

Галисия, которая расположена на северо-западе Пиренейского полуострова и с двух сторон омывается водами Атлантики, ассоциируется в сознании среднестатистического испанца с краем земли, т. е. местом, где заканчивается какая-либо цивилизация. Не случайно одним из топонимов, который можно смело вписать в визитную карточку Галисии, является Finisterre (край земли). Иными словами, речь идет об испанском захолустье. 
Самих галисийцев жители других регионов Испании считают людьми работящими, очень гостеприимными, но в то же время не вызывающими особого доверия, поскольку невозможно предугадать, что сделает галисиец в следующую минуту. Его образ ассоциируется с лестницей, которая ведет как вверх, так и вниз. Более того, галисиец никогда не ответит прямо на поставленный вопрос. В лучшем случае ответом прозвучит depende ¿no?

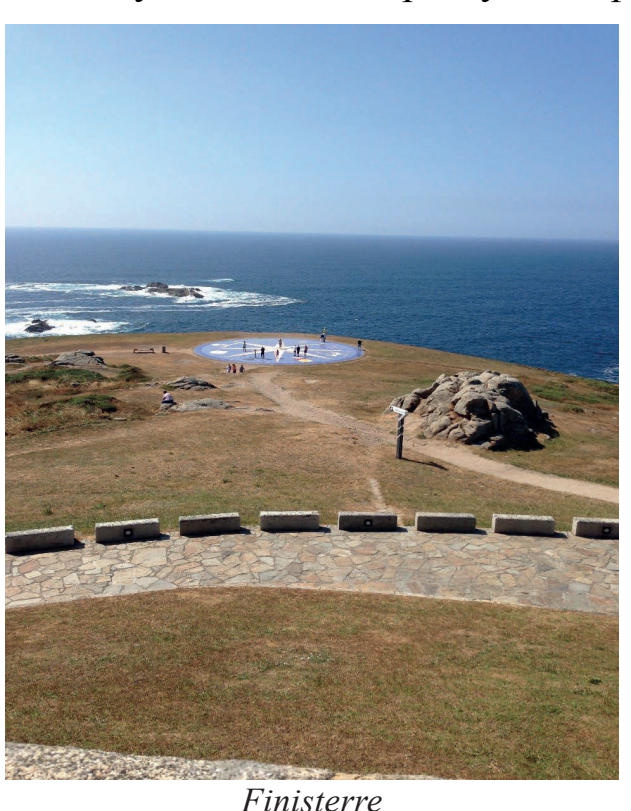

Трудолюбие и жажда приключений заставляют галисийца пускаться в путь в поисках работы, что нашло отражение в следующей поговорке: «Allí donde vayas te encontrarás con un gallego». Однако справедливости ради следует подчеркнуть, что массовая миграция галисийцев все же вызвана тем тяжелым социально-экономическим положением, которое было характерно для этого региона на разных этапах его истории и оставляет желать лучшего и сегодня.

Кстати, испанцев, эмигрирующих в Южную Америку, как правило, называют галисийцами, несмотря на то что они могут быть выходцами из разных регионов Испании. Это связано с тем, что подавляющее большинство эмигрантов составляют именно галисийцы. По данным, которые приводит Б.П. Нарумов, в странах Нового Света проживает более 1 миллиона эмигрантов и их потомков родом из Галисии [Нарумов 2008: 4]. Так, в Аргентине эта цифра достигает примерно 70\% от общего числа испанской диаспоры. При этом слово gallego приобрело такие носящие уничижительный характер оттенки значений, как человек недалекий, жадный и ненадежный.

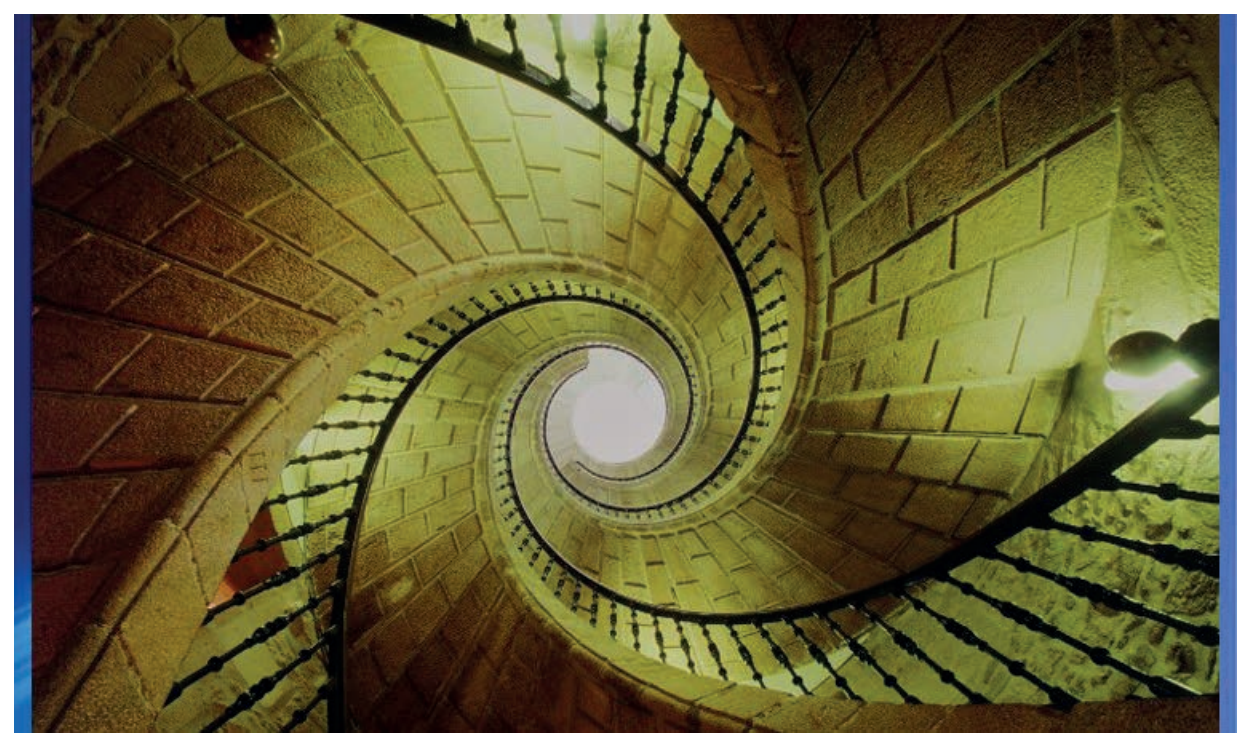

Метафорический образ галисийцฺ

Другим распространенным стереотипом является представлением о том, что Галисия, будучи где-то на краю света, населена такими мистическими и сказочными персонажами как meigas. Это злые колдуньи, которые способны нанести вред 
и совершить любое злодеяние по отношению к человеку. Именно из галисийского языка распространилось такое крылатое выражение, как «Eu non creo nas meigas, mais habelas, hainas» («Yo no creo en las meigas, pero haberlas, las hay»), которое можно истолковать следующим образом: «Я не верю в существование ведьм, но если их нельзя увидеть, это не значит, что их нет». Живучесть этого выражения свидетельствует о том, насколько крепко в характере галисийца укоренились и переплелись практичность и склонность к мистицизму.

Существует еще много стереотипов, которые, безусловно, всегда жили и будут жить в сознании самих галисийцев, их соседей и других народов, с которыми жителям Галисии доводилось соприкасаться. Однако действительно ли Галисия, будучи отдаленной провинцией Испании, является настоящим захолустьем, краем света, богом забытой землей, очень бедной, откуда люди бегут, потому что нет возможности найти работу, и т. д.?

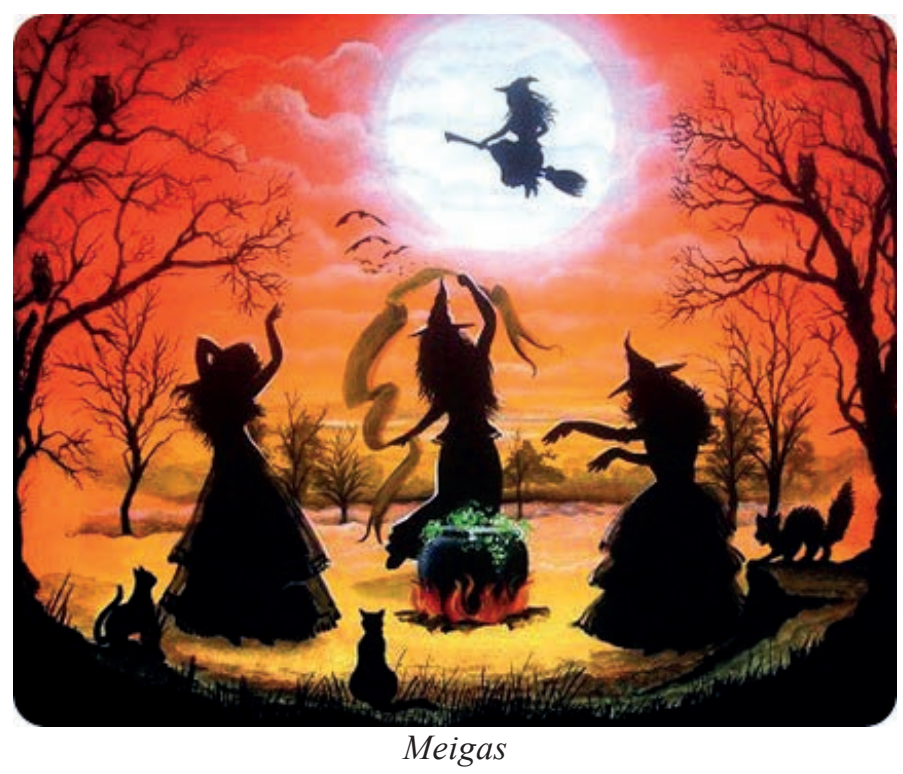

Стоит приехать в Галисию, чтобы понять, что представление об этой земле среднестатистического испанца далеко не совпадает с тем, что думают сами ее жители, и с тем, что подтверждается реальными фактами.

Выгодное географическое положение, а именно - выход в Атлантику, подсказывает, что Галисия как в далеком прошлом, так и сегодня находится на пересечении важных торговых и культурных путей, благодаря чему галисийцы чувствуют свою причастность многим важным событиями европейской истории, а также явлениям культурного и религиозного характера.

Обзор ключевых моментов истории развития этого региона Испании и характеристику каждого из этапов дает Б.П. Нарумов в своей монографии, посвященной галисийскому языку [Нарумов 2008: 7-45].

Одним из самых впечатляющих и фантастических мифов стала попытка представить Галисию как территорию, откуда берут свое начало кельты. В 2009 г. был создан галисийский институт кельтских исследований Instituto Galego de Estudos Célticos (IGEC), задача которого изучать и сохранять те элементы кельтской культуры, которые были найдены на территории Галисии.

Особые надежды сторонники теории галисийского происхождения кельтов возлагали на исследования Анхеля Карраседо, руководителя медицинского ин- 
ститута Университета Сантьяго де Компостела, полагая, что полученные этим специалистом по генетике данные помогут доказать их гипотезу и подтвердить подлинность легенды о Бреогане.

Согласно этой легенде, в городе Бригантия (некоторые археологи склоняются к мысли, что это А Корунья) король Бреоган построил высокую башню, откуда был виден далекий зеленый берег (имеется в виду южная Ирландия). Тогда один из сыновей Бреогана отправился туда и был убит. И вот внуки Бреогана, охваченные жаждой мести, отправляются в военный поход и захватывают Ирландию и другие британские острова. Эта красивая сказка лежит в основе ирландских эпических произведений XI в. и говорит нам о том, что уже в ту раннюю эпоху существова-

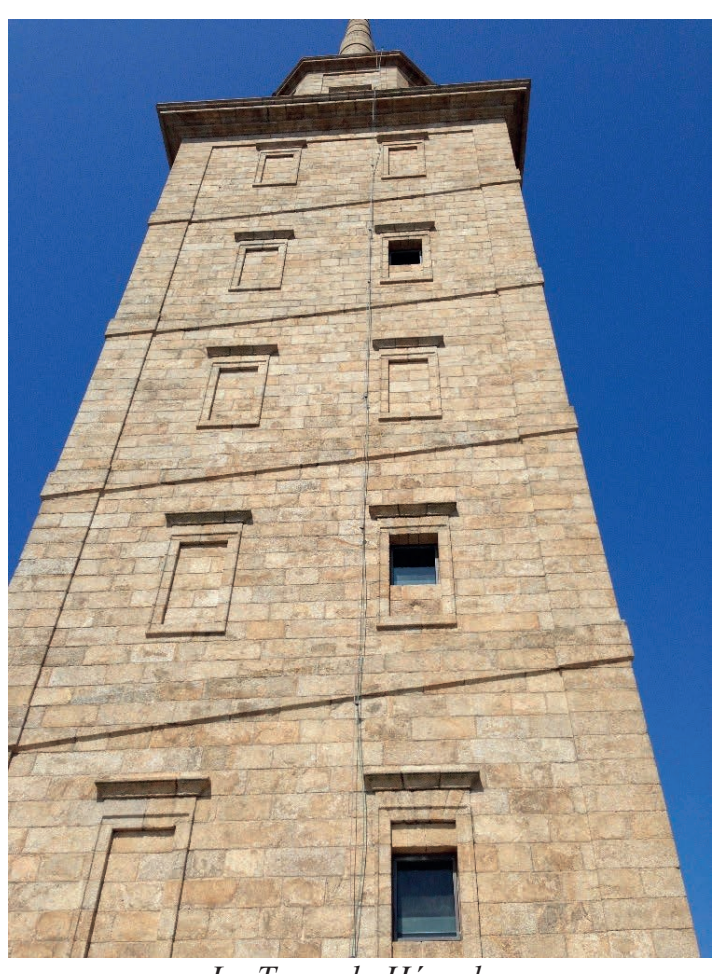

La Torre de Hércules ли контакты между народами в бассейне Атлантического океана, но достоверные доказательства, которые подтверждали бы хронологическую последовательность событий и причинно-следственные связи между ними, отсутствуют. Выступая на III Международном конгрессе по кельтской культуре в 2011 г., Анхель Карраседо подчеркнул, что проводимые им исследования по хромосомам и ДНК могут доказать лишь общность генетического происхождения, но не могут пролить свет на общность культуры и языка [Salgado 2015]. По его мнению, кельтские племена могли перебираться в Галисию, спасаясь от сильных морозов.

В Галисии сохранились древние памятники в виде укреплений (castro), самый древний из действующих маяков (La Torre de Hércules), воздвигнутый римскими колонизаторами на месте предыдущего, о характеристиках которого можно только гадать, и красивая легенда о короле Бреогане, которую не удалось использовать для достижения определенных идеологических, а возможно, и политических целей.

Другим заметным явлением культурной жизни Западной Европы стала лирика средневековых галисийских трубадуров, вдохновленных славой своих провансальских и каталанских собратьев по перу. Провансальская лирика, ориентированная на запросы аристократов королевских дворов, пользовалась невероятным успехом не только в Провансе и Каталонии, но и при королевских дворах соседей. При этом все стремились подражать первым и поэтому признанным лучшими трубадурам. Язык поэзии трубадуров, своего рода литературное койне, считался общепризнанным поэтическим языком и использовался всеми трубадурами, невзирая на то, откуда они родом. Однако галисийские трубадуры, воспитанные на лучших провансальских образцах, все же пошли своим путем и оставили богатейшее поэтическое наследие на галисийско-португальском языке. Творчеству средневековых португальских и галисийских трубадуров посвящена монография О.А. Сапрыкиной «Язык и словесное творчество средневековой Португалии». Ее автор подчеркивает, что «уже в конце XII в. галисийско-португальский язык был 
известен и признан за пределами Пиренейского полуострова как язык своеобразной лирической поэзии» [Сапрыкина 2010: 102].

Престиж этого языка был настолько высок, что он был признан как язык поэзии при королевском дворе Кастилии. По мнению О.А. Сапрыкиной, «Поэзия галисийско-португальских трубадуров, расцвет которой произошел в XIII в., наследует разнообразные традиции. Одна из них традиция древнейшей народной испанской поэзии - восходит к мифопоэтической словесности. Другая традиция, литературная, проходит через творчество провансальских трубадуров XII в. Третья традиция сложилась в арабоандалусской средневековой поэзии» [Сапрыкина 2010: 110].

Но возникает вопрос, как при отсутствии современных средств передвижения и коммуникации поддерживались тесные культурные связи и так быстро распространялась информация в Средние века? С этой задачей великолепно справлялись

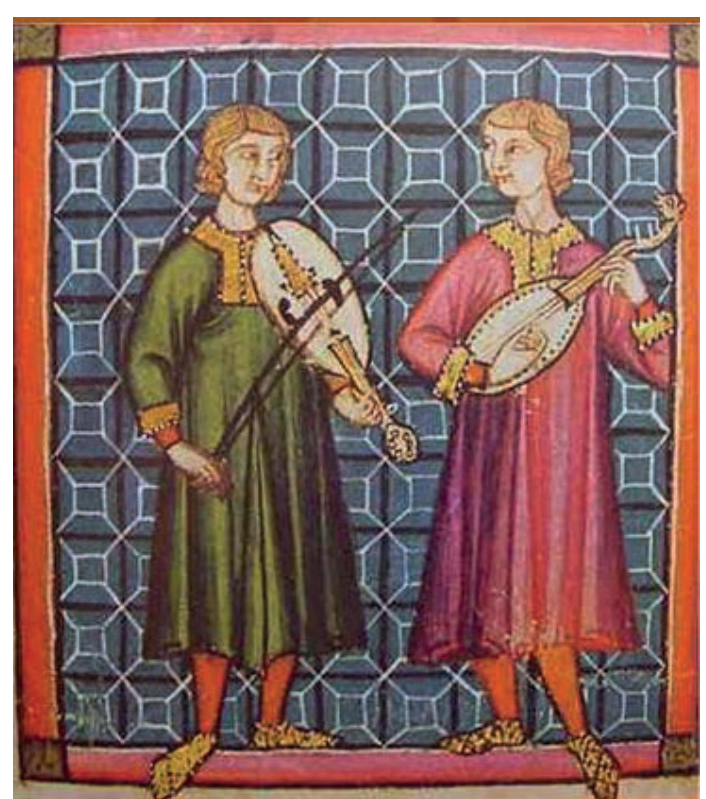

Средневековая галисийская поэзия паломники.

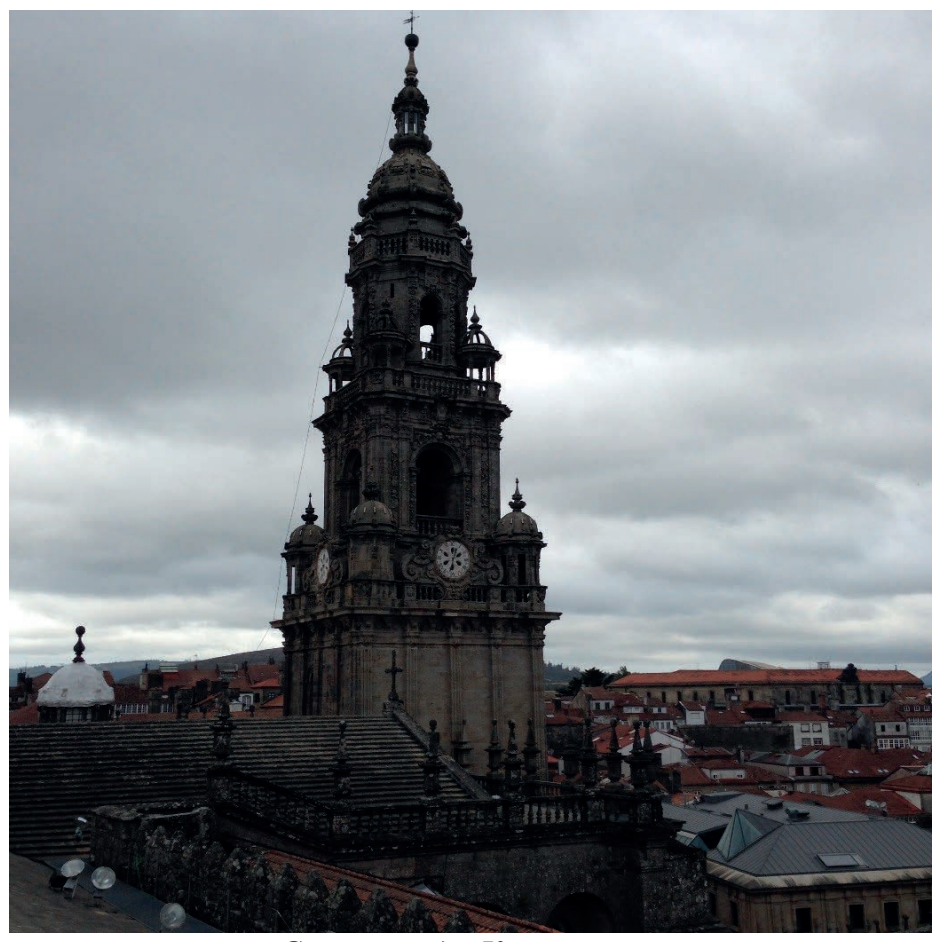

Сантьяго де Компостела

C того момента, когда в IX в. в Сантьяго де Компостела были найдены реликвии и весь христианский мир узнал, что там хранятся мощи святого апостола Иакова (хотя научных доказательств этого не существует, все держится на вере), Галисия постепенно становится одним из влиятельных христианских центров, притягивая католических паломников отовсюду, что в свою очередь способству- 
ет возвышению города: отстраиваются кафедральный собор, университет и другие монументальные здания религиозного и гражданского характера. К XVI в. престиж и влияние Сантьяго де Компостела резко падает, что ведет к резкому снижению числа паломников. Религиозная жизнь замирает на несколько веков. А новый всплеск интереса к Сантьяго де Компостела происходит к концу XX в., и сегодня ежегодно, особенно летом, толпы паломников заполняют улицы и площади этого великолепного средневекового города. Таким образом, Богом забытая земля - это уж точно не про Галисию.

Как раз потому, что в Сантьяго де Компостела слишком много приезжих, очень трудно расслышать в этом многоязыком гомоне галисийскую речь. Но она все же звучит: 95\% жителей Галисии считают галисийский родным [Гринина 2014: 46]. В глаза бросаются надписи, сделанные на галисийском; в книжном магазине полки ломятся от обилия литературы на галисийском языке. Тем не менее галисийская молодежь предпочитает использовать испанский язык, который оказывается более конкурентоспособным, прежде всего на рынке труда. При этом галисийскому языку приходится конкурировать не только с испанским, но и с английским. К подобному положению привели реформы, предпринятые в области образования. Разделяя мнение защитников галисийского языка, А.А. Евдокимова подчеркивает: «...правительство Галисии фактически ведет тайную войну против галисийского языка» [Евдокимова 2013: 70].

Анализ современной языковой ситуации в Галисии показывает, что процесс языковой нормализации галисийского языка, несмотря ни на что, движется вперед и проходит гораздо спокойнее, чем в других автономных областях Испании, как, например, в Каталонии или Валенсии, где возникли течения, которые, в угоду политическим амбициям, по утверждению Г.В. Денисенко, упорно отрицают, что el valenciano это каталанский язык. [Денисенко 2016: 573-574]. И хотя в Галисии никто не призывает к сепаратизму, споры между сторонниками языковой интеграции с Португалией и их противниками бывают очень жаркими [Евдокимова 2012: 217].

Будущее покажет, какие результаты даст языковая политика, проводимая правительством Галисии, и чем закончатся споры между сторонниками языковой интеграции с Португалией и их противниками. Однако приведенные примеры показывают, что, несмотря на удаленность от центра страны, Галисия всегда находилась и по-прежнему находится на перекрестке многих дорог, как ведущих в другие уголки Европы, так и - через Атлантику - на другие континенты.

\section{ЛИТ Е РАТ У РА}

Гринина E.A. Situación sociolingüística en España: el pasado y el presente. Мир испанского языка: курс лекций по лингвострановедению / Под ред. А.А. Горенко, Е.В. Крюковой. М.: МГИМО-Университет, 2014. С. 38-60.

Денисенко Г.В. La Guerra por la lengua: ¿el catalán/el valenciano o el catalán y el valenciano? // Ибероамериканский мир: традиции и современные тенденции. Приложение к журналу «Ибероамериканские тетради». Материалы VII Международной научной конференции испанистов: «Ноmo loquens в ибероамериканском лингвистическом пространстве: исследование и преподавание». Вып. 1. М.: МГИМО, 2016. С. 572-578.

Евдокимова А.А. Галисия: на пороге лингвистических войн // Ибероамериканские тетради. Вып. 1 / Отв. редактор А.А. Орлов. М.: МГИМО-Университет, 2013. С. 70-75. 
Евдокимова A.A. El gallego: ¿isolación o reintegración? // V Международная научная конференции испанистов: «Испанский язык в контексте новых вызовов XXI века: исследования и преподавание» (26-28 апреля 2012 г.). М.:Изд-во МГИМО-Университет, 2012. С. 216-217.

Нарумов Б.П. Формирование романских литературных языков. Современный галисийский язык. 2-е изд., доп. М.: Издательство ЛКИ, 2008. 166 с.

Сапрыкина О.А. Язык и словесное творчество средневековой Португалии. М.: КРАСАНД, 2010. 285 c.

Salgado X. ¿Descienden los celtas de los gallegos? www.elmundo.es/elmundo/2011/04/15/ galicia/1302889574.html

\section{REFERENCES}

Grinina E.A. Situación sociolingüística en España: el pasado y el presente. The World of the Spanish Language: A course of Lectures on Linguistics. Moscow MGIMO-University Press, pp. 38-60.

Denisenko G.V. The War for the Language: the Catalan / the Valencian or the Catalan and the Valencian? In: The Ibero-American World: Traditions and Modern Trends. Issue 1. Moscow. MGIMO-University Press. 2016, pp. 572-578.

Evdokimova A.A. Galicia: On the Threshold of Linguistic Wars. In: Cuadernos Iberoamericanos. Issue 1. Moscow. MGIMO-University Press. 2013, pp. 70-75.

Evdokimova A.A. El gallego: ¿isolación o reintegración? In: V International Scientific Conference of Spanish: "Spanish in the Context of the New Cchallenges of the $21^{\text {st }}$ century: Research and Teaching” (26-28 April 2012). Moscow. MGIMO-University Press. 2012, pp. 216- 217.

Narumov B.P. (2008) The Formation of the Romance Literary Languages. The Modern Galician Language. $2^{\text {nd }}$ ed., suppl. Moscow. URSS Publ. 166 p.

Saprykina O.A. (2010) Language and Verbal Creativity of Medieval Portugal. Moscow. KRASAND Publ. 285 p.

Salgado X. ¿Descienden los celtas de los gallegos? www.elmundo.es/elmundo/2011/04/15/ galicia/1302889574.html

Сведения об авторе:

\author{
Елена Анатольевна Гринина, \\ канд. филол. наук \\ доцент \\ Московский государственный институт \\ международных отношений (Университет) \\ МИД России (МГИМО-Университет)
}

Elena A. Grinina,

PhD (Romance Linguistics)

Associate Professor

Moscow State University of International Relations

(MGIMO-University) 